\title{
Control as an Engagement Feature for Young Children's Attention to and Learning of Computer Content
}

\author{
SANDRA L. CALVERT \\ BONNIE L. STRONG \\ LIZANN GALLAGHER \\ Georgetown University
}

\begin{abstract}
This article examines a study in which young children were exposed to a computer story that varied the amount of control that children had over the visual and verbal content. Children who controlled the computer demonstrated more attention and involvement than those who watched an adult control the experience. Boys who had an adult control the program were more likely to try to gain control of the activity by making attempts to get the mouse or by asking to change activities. Control, however, had no effect on children's memory of visual or verbal content. The implication is that control is an engagement feature that has its greatest impact when examining attention and interest, a lesson that may facilitate constructive early adult-child interactions with educational computer software.
\end{abstract}

New interactive media are now integrated into the fabric of children's daily lives (Rideout, Vandewater, \& Wartella, 2003). Online programs for very young children are routinely accessible, and promises of enhanced learning from this potential new form of education abound. For young children, this means early computer experiences that focus on preacademic skills, such as prereading activities, can be targeted.

Interactivity is highlighted as the mechanism that will enhance children's attentional interest and learning from the newer media. Interactivity can be defined as an exchange of actions or ideas that builds on previous exchanges

Authors' Note: This research was supported by Grant No. 0126014 from the National Science Foundation. We thank the teachers, students, and parents of Washington International School, Horace Mann Elementary School, and the Hoya Early Child Care Center for their assistance with this research. We also thank Sean Zehnder, Edward Gonzales Jr., Alison Kuhl, Katherine Murray, and Emily Conger for their assistance in conducting this research. Requests for reprints should be directed to Sandra L. Calvert, Director, Children's Digital Media Center, Department of Psychology, 309-C White Gravenor Building, Georgetown University, 37th \& O Streets, N.W., Washington, DC 20057; e-mail: calverts@georgetown.edu.

AMERICAN BEHAVIORAL SCIENTIST, Vol. 48 No. 5, January 2005 578-589

DOI: $10.1177 / 0002764204271507$

(C) 2005 Sage Publications 
(Rafaeli, 1988). Interactivity, embedded in human experiences, involves control, responsiveness, and turn taking (Sims, 1997; Wartella \& Jennings, 2000).

In the study conducted here, we examined interactivity in terms of varying degrees of child control of the learning experience. We were interested in how control affected young children's attention to, and subsequent learning of, visual and verbal content adapted from an online children's storybook. Our major hypotheses were that personal control would enhance children's attentional interest in the program but that adult control would enhance children's learning of the targeted verbal program content.

\section{INTERACTIVITY: CONTROL AND CHILDREN'S LEARNING}

Interactivity is not unique to newer media. It has its core in human interaction processes that occur from the first moments of life when mothers and their newborn infants develop mutually responsive turn-taking skills (Shonkoff \& Phillips, 2000). This responsive environment allows the infant to experience contingent replies to his or her actions and to learn how to control early communicative and social exchanges.

How the child relates to a computer may have its roots in the early relational structures built in human relationships. A medium is interactive when it allows a responsive exchange, just as in human relationships. Well-structured computer software depends on turn taking (the child's turn, the computer's turn), contingent immediate responses to a child's actions (providing specific replies to what a child does), and control over the learning situation (making it possible for the child to pursue his or her own interests at his or her own pace).

Personal control, the target of our inquiries here, may facilitate attention and interest because children may be more engaged in activities that they choose to do. However, adult control may facilitate learning because adults can direct children to important program content.

\section{PRODUCTION FEATURES AND CHILDREN'S LEARNING}

The kind of content that children selectively remember early in life favors visual as opposed to verbal learning (Hayes \& Birnbaum, 1980). However, American parents and the American educational system are much more invested in verbal literacy than in visual or audiovisual literacy (Calvert, 1999). Efforts to enhance preliteracy skills, such as vocabulary and word recognition, are emphasized by educational media in the early years of life (Anderson, Huston, Schmitt, Linebarger, \& Wright, 2001). On one hand, visual content can even enhance young children's learning and memory of verbal content, particularly when the visual content supports and supplements the verbal material (Calvert, 1999). On the other hand, interesting visual techniques can also distract children from learning the verbal material, a phenomenon known as the visual superiority hypothesis (Hayes \& Birnbaum, 1980). For media production values to 
augment verbal learning, visual content should supplement and reinforce the verbal auditory track (Calvert, 1999).

Young children enjoy hearing stories (Snow, 1993), and embedding important linguistic content within a televised story can facilitate language development (Linebarger \& Walker, 2005 [this issue]). Viewing the same stories repeatedly, presented in book or televised formats, also helps young children learn the content (Crawley, Anderson, Wilder, Williams, \& Santomero, 1999; Snow, 1993). However, if educational material is not seamlessly embedded into the story, then narrative dominance may occur. That is, children will allocate their attention to learning the story content at the expense of targeted verbal material (Fisch, 2000; Lee \& Huston, 2003). Not surprisingly, software created for children often contains lessons embedded in a story, but those stories contain visual content that can potentially enhance or distract youngsters from understanding the targeted verbal educational content.

\section{GENDER PATTERNS}

Although the evidence is sometimes mixed, patterns of learning suggest that girls enjoy an advantage over boys in language development (Maccoby, 1998). In particular, at early ages, girls seem to acquire vocabulary sooner and use language more so than boys (Maccoby, 1998; Ruble \& Martin, 1998).

Boys tend to remember visually presented content better than girls, and girls tend to remember verbally presented content better than boys (Calvert, 1999; Greenfield, 1993). Girls' learning of important content also benefits more so than boys' learning when an adult verbally labels televised content; by contrast, boys tend to act on and master important content after engaging in programrelated activities such as role-playing (Friedrich \& Stein, 1975). Taken together, these findings suggest that boys may focus on and learn more from visually presented, action-based material, whereas girls may benefit more from adult verbal labeling of content.

Boys also act in agentic ways that are in keeping with the masculine role more so than girls do. For instance, young boys tend to be more aggressive and, hence, more assertive than young girls (Maccoby, 1998; Ruble \& Martin, 1998). Therefore, we expected young boys to exert more control-directed efforts than young girls, particularly when an adult was solely controlling the computer experience.

\section{THE PRESENT STUDY}

The purpose of this study is to examine the effect of user control on children's attention to, and learning of, content presented in a computer story.

\section{HYPOTHESES}

Based on the literature on control and attention, we hypothesized that 
Hypothesis 1: Children will be more attentive when they have more rather than less control in a computer learning experience.

Hypothesis 2: Children, particularly boys, will make more efforts to take control of the activity when they have less rather than more control of the computer learning experience.

Based on the literature on production features, gender, and informationprocessing skills, we hypothesized that

Hypothesis 3: Children, particularly boys, will learn more visual information when they have control of the learning situation because they will be more invested in the visual content.

Hypothesis 4: Girls will learn more verbally presented content than boys, particularly when an adult mediates and directs their attention to the verbal content.

Hypothesis 5: Children will learn more verbal information when they share control with an adult or when the adult controls the computer learning experience because left to their own devices, children will focus on the visual more than the verbal content.

Early reading skills are expected to serve as a moderator of our predictions and, thus, we hypothesized that

Hypothesis 6: Better readers will show more interest in, and learning of, verbal written content.

\section{METHOD}

\section{PARTICIPANTS}

Participants were 53 preschool-aged children ( $M=4$ years, 8 months, $S D=6$ months) who attended one of three facilities (one public primary school, one private primary school, one private day care facility) in Washington, D.C. There were 24 boys and 29 girls, representing Caucasian (62\%), Latino (9\%), Asian (9\%), African American (8\%), Indian/Middle Eastern (6\%), and other mixed/ unknown ethnic groups (6\%).

\section{STIMULUS AND TREATMENT CONDITIONS}

An online Nickelodeon Blue's Clues storybook, titled Blue Is My Name, was the stimulus for this study. The story has 13 pages. The words of the story are written in the upper-left-hand corner of the screen. When the cursor is rolled over the targeted vocabulary items, a pictorial representation of the written content appears. For instance, when the word blue is rolled over with the mouse, a visual image of the character, Blue, appears on the screen, with the word 
appearing below the image in a smaller font. The child does not hear the words unless the adult experimenter reads them aloud.

On the remainder of the screen, a picture of story events appears. When many of the visual icons are rolled over, interesting visual and auditory effects occur. For instance, when the icon of a mother bird is rolled over with the mouse, she releases worms into the mouths of her baby birds who are making "peeping" noises to be fed. A musical soundtrack plays throughout the story.

The story was reprogrammed so that only central story material moved or made interesting sounds to ensure that the incidental content (e.g., bubbles popping) was not distracting to children. Central story content was defined as plotrelevant content that was necessary to understand the narrative (Collins, 1970). Incidental story content was the content that was irrelevant to the plot (Collins, 1970). Another type of central content studied here involved the targeted written vocabulary items that changed from icons into words when scrolled over with the cursor.

This edited story was presented four times in one of four conditions: (a) an adult control condition in which the adult controlled the mouse and read the story as the child observed what was occurring, (b) a joint control condition where the adult and child took turns interacting with the content (i.e., the adult read the story and the child then explored the content and advanced the pages), (c) a child control condition in which the child was told that he or she could control the mouse as the child interacted with the program, and (d) a no-exposure condition where children answered the subsequent comprehension measure but never saw or interacted with the actual computer program.

\section{PROCEDURE}

Children participated individually in their respective randomly assigned computer treatment condition for two sessions with an adult. There were two repetitions of the story for each session on 2 different days of the same week. The first session was approximately 10 minutes in length, and the second was approximately 20 minutes in length because we asked comprehension measures at the end of Session 2. Children in the no-exposure condition participated in only one 10-minute session where they answered the comprehension measure.

Visual attention. Visual attention during the two sessions was videotaped using a digital camcorder. A trained observer scored eyes "on" and "off" the computer screen. Interobserver reliability, calculated as the duration of time for exact overlap of onsets and offsets of looks, was $99 \%$ for eyes on screen and $90 \%$ for eyes away from screen.

Control efforts. To examine children's efforts to take control of the experience, we later used the videotapes and written transcripts of the session to score three behaviors: (a) child requests to use the mouse, (b) child reaches for mouse, 
and (c) child requests to do a different activity. Interobserver reliability, computed as 2 times the number of agreements divided by the total number of scores, was $86 \%$.

Teacher evaluations of prereading skills. Children's teachers were asked to rate each child on his or her early reading skills on a 3-point scale where $1=$ does not recognize any words, $2=$ recognizes a few words, and $3=$ recognizes many words.

Comprehension measure. At the end of the second session, all children, including those in the control condition, were asked two kinds of questions: (a) those in which we examined recognition of the vocabulary words that were part of the written story $(n=14)$ and (b) those in which memory of the central visual story elements was examined $(n=7)$.

All written words that had been targeted in the computer story composed the verbal vocabulary recognition measure. A sample item examining verbal recognition of specific targeted words is "Point at the word for [picture of rain hat is shown, and the experimenter says the word rain hat]." The child then pointed at one of the following words: (a) Rain hat, (b) Shoes, or (c) Crayon.

The central story visual comprehension measure was created following procedures developed previously by Calvert (e.g., Calvert, 1992). Initially, a team of researchers targeted central and incidental content from the program and put them in an open-ended questionnaire. Then 20 undergraduate and graduate students rated each question as central or incidental to the program plot and wrote the answers to each question. Story items with a minimum centrality rating of $70 \%$ were retained. A sample item requiring recognition of central visual story content is "What color is Blue's favorite towel?" The experimenter then pointed at pictures of a purple, a red, and a blue towel, respectively.

The experimenter read each question aloud to each child who could select his or her response either by saying $A, B$, or $C$ or by pointing at a response choice. The experimenter circled the child's response selection on an answer sheet.

\section{RESULTS}

\section{ATTENTION TO THE COMPUTER PROGRAM}

A 2 (gender) $\times 3$ (condition) $\times 4$ (attention) repeated measures ANOVA was conducted with attention to the four program exposures as the repeated measures variable and reading level as a covariate. The analysis yielded a significant main effect of attention, Wilks's Lambda $=8.10, p<.001, \eta_{p}^{2}=.448$, and an Attention $\times$ Condition interaction, Wilks's Lambda $=2.59, p<.03, \eta_{\rho}^{2}=.206$. Follow-up analyses revealed significant differences in children's attention to the four program exposures within the adult control condition, Wilks's Lambda = 


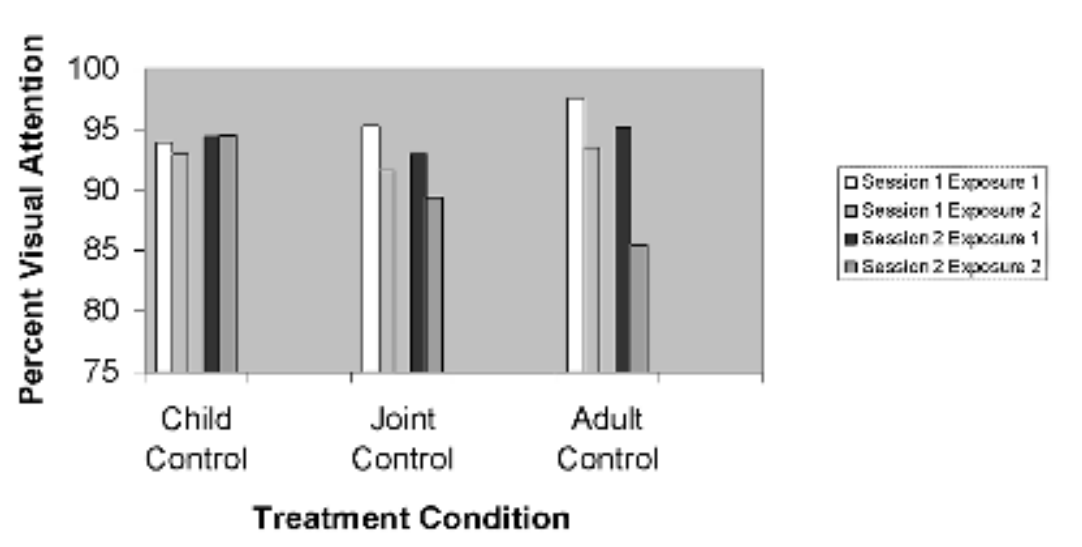

Figure 1: Attention to Program as a Function of Condition and Exposures

4.89, $p<.03, \eta_{\rho}^{2}=.62$; as well as a trend within the joint control condition, Wilks's Lambda $=3.12, p<.09, \eta_{\rho}^{2}=.5$; but not within the child control condition, Wilks's Lambda $=1.35$, n.s. These are strong effect sizes, particularly given the relatively small sample size of this study.

As seen in Figure 1, attention to the computer program during the child-control condition was relatively consistent across the two sessions and four repetitions of the activity. By contrast, in both conditions where the adult controlled parts or all of the interaction, children's attention declined from the first to the second repetitions for both sessions. These drops in attention were especially steep in the second session when the adult controlled the entire activity, suggesting increased habituation and loss of interest with time when adults use a controlling interaction style.

\section{EFFORTS TO CONTROL TASK: ASKS FOR OR REACHES FOR MOUSE OR REQUESTS CHANGE OF ACTIVITY}

We expected children, particularly the boys, in the adult control condition to put forth more efforts to control the story they were observing than children in the child control or joint control conditions. Efforts to take control of the activity were gauged by requests for the mouse, whether physical or verbal, plus requests to do a different activity. Control efforts were summed across all sessions. A 3 (condition) $\times 2$ (gender) ANCOVA was conducted on control efforts with reading level as a covariate.

The two-factor ANCOVA computed on control efforts yielded a main effect for gender, $F(1,37)=4.49, p=.04$, which was qualified by a Condition $\times$ 
TABLE 1: Efforts to Control Task as a Function of Condition and Gender

\begin{tabular}{|c|c|c|c|c|c|c|}
\hline & \multicolumn{2}{|c|}{ Mean } & \multicolumn{2}{|c|}{ Standard Deviation } & \multicolumn{2}{|c|}{ Sample Size } \\
\hline & Boys & Girls & Boys & Girls & Boys & Girls \\
\hline Child control & 0.67 & 0.00 & 1.03 & 0.00 & 6 & 7 \\
\hline Joint control & 2.00 & 2.50 & 2.53 & 2.88 & 6 & 6 \\
\hline Adult control & 7.33 & 1.84 & 10.17 & 1.86 & 6 & 7 \\
\hline
\end{tabular}

Gender interaction, $F(1,37)=3.29, p=.05$. The reading competency covariate was also significant, $F(1,37)=4.73, p<.04$, with better readers making more efforts to control the activity. As predicted, boys made more efforts to control the activity than girls did, particularly in the adult control condition (see Table 1).

\section{LEARNING STORY CONTENT AND VOCABULARY RECOGNITION}

Visual learning. A 2 (gender) $\times 4$ (condition) ANCOVA was conducted with reading level as the covariate and learning the visual story content as the dependent variable. The two-factor ANCOVA computed on visual learning scores yielded a main effect of condition, $F(1,44)=7.05, p=.001$. Not surprisingly, children in any Blue's Clues treatment condition recognized more visual content than the no-exposure control group did. Means were $5.64(S D=.74)$ for the adult control condition, followed by $5.54(S D=1.05)$ for the child control condition, $5.38(S D=.96)$ for the joint control condition, and 4.00 for the no-exposure condition $(S D=1.29)$.

As expected, boys tended to recognize more visual story material than girls did, but this predicted advantage emerged only as a trend, $F(1,44)=3.27, p<.08$ (boys, $M=5.41, S D=1.18$ vs. girls, $M=4.93, S D=1.19$ ). Children's reading skills had no impact on their recognition of visually presented content, nor did those in the child control condition show any benefits for memory of the visual content. Put another way, most children remembered the visually presented content relatively well.

Verbal learning. A 2 (gender) $\times 4$ (condition) ANCOVA was conducted with reading level as the covariate and learning the targeted words as the dependent variable. The two-factor ANCOVA computed on verbal learning scores yielded a main effect for the covariate of reading level, $F(1,44)=4.61, p<.04$. Better readers recognized more words than poorer readers. Contrary to prediction, there were no effects of condition or of gender in the overall ANCOVA. 


\section{DISCUSSION}

The purpose of this study was to examine the effects of adult control on young children's attention to, and memory of, content presented in a computer story. As expected, children were less interested in the story and became less attentive across repetitions when an adult controlled the situation and children had little personal control of the learning situation. These drops in attention were steepest when the adult had total control of the mouse, particularly in the last session. By contrast, when children controlled the session, there was never a significant drop in attention across sessions, a finding that was unique to their group. The results suggest that user control plays an important role as an engagement feature that can facilitate children's attention to and interest in computer activities.

Even though there were variations in attention across treatment conditions, overall attention was relatively high, with averages across sessions generally at more than $90 \%$ except for the last exposure for children in the adult control condition. This high level of attention may have occurred because there was little else for children to do during the sessions, although some did wander off task, looking around the room. Children also became less attentive and made more requests to change activities during sessions when they could only watch what the adult was doing. Efforts to take control were particularly pronounced for boys, who are generally more aggressive and, hence, more assertive than girls in their interaction styles (Maccoby, 1998; Ruble \& Martin, 1998).

In contrast to the attention findings, there were no differences across conditions in examining children's memory of the content. We tapped into both visual and verbal measures of memory. For recognition of visual story-related responses, the only treatment difference was between all treatment conditions and the control group who received no exposure to the content. Consistent with previous literature (see Calvert, 1999), boys tended to remember more visually presented content.

For comprehension of the targeted written words, only reading skills predicted children's recognition of specific written words that had been presented in the story. Our findings did not support those found in the television literature where adult mediation improves children's learning of content, particularly girls' learning of verbally presented content (e.g., Friedrich \& Stein, 1975). Instead, we found no impact of adult mediation on children's learning of verbal content, and attention was actually higher with time when the adult followed the child's lead for interactive media.

The failure of children to remember verbally presented material from the presentation, even after mastering the visually presented content, can be interpreted in at least two ways. First, our findings are consistent with previous research documenting a visual superiority hypothesis in which children direct their 
attention and remember the visually presented content at the expense of the verbally presented content (Hayes \& Birnbaum, 1980). Second, the findings also point to the problem of narrative dominance: That is, children allocate their attention to understanding the story at the expense of the targeted verbal educational material when the vocabulary items are not tightly woven into the plot line (Fisch, 2000; Lee \& Huston, 2003). Contrary to Fisch's (2000) recommendation, a simple story does not necessarily lead children to invest more resources into understanding academic content, at least when the narrative is not closely linked to the learning activity. That children's visual attention increasingly drops off with time in conditions when the adult controls the mouse and reads the story is suggestive: Children, particularly boys, seem to get bored across repetitions when they are not in charge of the activity.

Although control did not have major effects on young children's learning, there are some caveats. Because repetition enhances learning of televised media content at young ages (Crawley et al., 1999), the repetition of the computer program may have led to a ceiling effect for learning the visually presented content. A repetition effect may have been exacerbated because we highlighted only central story content, thereby reducing potential content distractions. However, children are exposed to the same books repeatedly, so repetition is the normative experience (Snow, 1993).

Another caveat of the findings is that young children are used to adults reading to them, giving them directions, and controlling the activity in ways that an older age group may not readily accept. Further examination of how various control strategies influence children's engagement, attention, and learning are warranted, particularly at older ages.

A third issue is that the children in the adult control condition observed the content even if they did not interact with it. There is a long tradition of children learning by observing television content (see Bandura, 1986). In fact, in the current study, observing seems just as effective for learning as is interacting with the content. Thus, we may be underestimating observation as a tool for learning in our new interactive media world.

Finally, the verbal and the visual content were not well integrated in our computer story, with each appearing in separate locations of the screen. If the written words were seen and heard when children rolled over the visual icon embedded in the story, then perhaps comprehension of written words might improve. Learning the words could also potentially be augmented if a character asked the child to say the word with them to increase rehearsal activities.

In conclusion, with increased exposure, visual attention declined when children had little control of their exposure to the same computer content. However, control had little impact on their memories of the content. The results suggest that control has its greatest effect as an engagement feature that can facilitate young children's interest in and attention to computer-presented content. 


\section{REFERENCES}

Anderson, D. R., Huston, A. C., Schmitt, K. L., Linebarger, D. L., \& Wright, J. C. (2001). Early childhood television viewing and adolescent behavior: The Recontact Study. Monographs of the Society for Research in Child Development, 68(1, Serial No. 264).

Bandura, A. (1986). Social foundations of thought and action. Englewood Cliffs, NJ: Prentice Hall.

Calvert, S. L. (1992). Pictorial prompts for discursive analyses: Developmental considerations and methodological innovations. American Behavioral Scientist, 36, 39-51.

Calvert, S. L. (1999). Children's journeys through the information age. New York: McGraw-Hill.

Collins, W. A. (1970). Learning of media content: A developmental study. Child Development, 41, 1133-1142.

Crawley, A. M., Anderson, D. R., Wilder, A., Williams, M., \& Santomero, A. (1999). Effects of repeated exposures to a single episode of the television program Blue's Clues on the viewing behaviors and comprehension of preschool children. Journal of Educational Psychology, 91, 630-637.

Fisch, S. (2000). A capacity model of children's comprehension of educational content on television. Media Psychology, 2, 63-91.

Friedrich, L. K., \& Stein, A. H. (1975). Prosocial television and young children: The effects of verbal labeling and role playing on learning and behavior. Child Development, 46, 27-38.

Greenfield, P. M. (1993). Representational competence in shared symbol systems: Electronic media from radio to video games. In R. R. Cocking \& K. A. Renninger (Eds.), The development and meaning of psychological distance (pp. 161-183). Hillsdale, NJ: Lawrence Erlbaum.

Hayes, D., \& Birnbaum, D. (1980). Preschoolers' retention of televised events: Is a picture worth a thousand words? Developmental Psychology, 16, 410-416.

Lee, J., \& Huston, A. C. (2003). Educational televisual media effects. In E. Palmer \& B. Young (Eds.), The faces of televisual media (pp. 83-106). Mahwah, NJ: Lawrence Erlbaum.

Linebarger, D. L., \& Walker, D. (2005). Infants' and toddlers' television viewing and language outcomes. American Behavioral Scientist, 48, 624-645.

Maccoby, E. E. (1998). The two sexes: Growing up apart, coming together. Cambridge, MA: Belknap Press.

Rafaeli, S. (1988). Interactivity: From new media to communication. In R. Hawkins, J. Wiemann, \& S. Pingree (Eds.), Advancing communication science: Merging mass and interpersonal processes (pp. 110-134). Newbury Park, CA: Sage.

Rideout, V. J., Vandewater, E. A., \& Wartella, E. A. (2003). Zero to six: Electronic media in the lives of infants, toddlers, and preschoolers. Menlo Park, CA: Kaiser Family Foundation.

Ruble, D., \& Martin, C. (1998). Gender development. In W. Damon \& N. Eisenberg (Eds.), Handbook of child psychology: Vol. 3. Social, emotional, and personality development (pp. 933-1017). New York: John Wiley.

Shonkoff, J., \& Phillips, D. (2000). From neurons to neighborhoods: The science of early childhood development. Washington, DC: National Academy Press.

Sims, R. (1997). Interactivity: A forgotten art? Computers in Human Behavior, 13, 157-180.

Snow, C. E. (1993). Families as social contexts for literacy development. New Directions for Child Development, 61, 11-24.

Wartella, E., \& Jennings, N. (2000). Children and computers: New technology—Old concerns. Children and Computer Technology, 10, 31-43.

SANDRA L. CALVERT is the director of the Children's Digital Media Center and a professor of psychology at Georgetown University. She is the author of Children's Journeys Through the Information Age (McGraw-Hill, 1999) and coeditor of Children in the Digital Age: Influences of Electronic Media on Development (Praeger, 2002). Her current research examines the role that interactivity and identity play in children's learning from 
entertainment media through studies conducted by the Children's Digital Media Center, a consortium offour universities funded by the National Science Foundation. She is a fellow of the American Psychological Association and consults for various companies to influence the development of media for children.

BONNIE L. STRONG worked as a manager in the media industry for 10 years, including preproduction for Walt Disney Feature Animation. From there, she moved into the technology industry as a corporate client manager for design and Web-based projects. She has a B.S. in speech from Northwestern University and is pursuing an M.A. in communication, culture, and technology from Georgetown University. She is also a member of the Children's Digital Media Center.

LIZANN GALLAGHER is a former member of the Children's Digital Media Center with a B.A. in psychology from Georgetown University. 